\title{
The Relationship Between Structure Empowerment and Job Characteristics of Staff Nurses At Mansoura Specialized Medical Hospital
}

\author{
Nervana Abdel-Rhman Gheith*
}

\begin{abstract}
Structure empowerment enhances nurses' power to accomplish their work within hospitals. Access to these empowering structures is influenced by formal power system within the hospital which refers to job characteristics that contribute to job recognition. So, job characteristics are the core to reach to excellent quality patient care and to achieve organizational outcomes. The purpose of this study is to determine the relationship between staff nurses' perception of structural empowerment and their job characteristics. The data were collected from 182 staff nurses working at Mansoura Specialized Medical Hospital. Two tools were employed for data collection. The first tool is structure job empowerment questionnaire which is divided into two parts: a) Conditions for Work Effectiveness Questionnaire (CWEQ) and b) Organizational Description Opinionnaire (ODO). The second tool is Staff Nurses Job Characteristics Index Questionnaire (SNJCIQ). The results concluded that there are a strong and significant relationship between staff nurses' perception of structure empowerment and their job characteristics. This study recommended that application of job characteristics model nutrients to empower staff nurses, and improve the quality of nursing care.
\end{abstract}

\section{INTRODUCTION}

The healthcare institutions are undergoing dramatic restructuring in response to managed care penetration and the quest for cost reduction. Many changes are being made that seem likely to affect nurses' jobs and empowerment ${ }^{1}$. Structure empowerment enhances nurses' power to accomplish their work within the hospital. Access to these empowering structures is facilitated by formal power system within the hospital which refers to job characteristics such as variety of skills, exploring identity of tasks, the importance of activities and significance of skills, improving relationships among nurses, and support from superiors and peers through feedback ${ }^{2}$. In addition, Wallach ${ }^{3}$ (2006) mentioned that Job characteristics are at the heart of empowerment and the core to reach to excellent quality patient care and to achieve organizational outcomes. Moreover, empowerment leads to increase autonomy which is an element of job characteristics ${ }^{4,5}$.

${ }^{\star}$ Nursing Administration, Faculty of Nursing, Mansoura University 
We begin with a necessarily cursory look at what is meant by empowerment. The Oxford English Dictionary ${ }^{6}$ defines empowerment as "to give power", "authority to", or "to sanction". In a sense then, it may be reasonable to say that nurses gain knowledge through the intrinsic power they assume in interpreting the human condition in patients during interactions with them.

Kanter $^{7,8}(1977,1993)$ mentioned that structural factors within the work environment, not inherent personality traits or socialization experiences, influence nurses' perceptions of empowerment and ultimately have an impact on their work behaviour. The structures within organizations that $\operatorname{Kanter}^{7,8}$ believes to be important for nurse empowerment are having access to opportunity, resources, information, and support.

Access to opportunity refers to an individual's expectations and future prospects for growth and advancement, inside or outside the organization. The opportunity for mobility and growth is determined by the access to challenge, rewards, professional committees, and task forces ${ }^{9}$. Opportunities for growth and development can be provided through staff development programs and problem-solving team that allows nurses to form new relationships, learn new skills and gain recognition by having the opportunity to demonstrate their abilities ${ }^{10}$.

Another structural empowerment factor is access to resources which refer to the capability of individuals to access the materials resources such as equipment, supplies, space, money, time, and rewards, and human resources that are necessary for efficiency and effectiveness of the healthcare organization ${ }^{11}$. Access to resources is the most critical empowerment factor. So that, managers and staff nurses can work together to determine resources and supplies that are required in their specific areas ${ }^{12}$.

In addition, having access to information is having access to organizational policies and goals, including the data, technical knowledge, and expertise required to function effectively in 
one's position within the broader context of the organization. In description of access to information, Laschinger and Havens ${ }^{13}$ mentioned that information is power, so, having information about plans, events, and activities which affect one's job is crucial, particularly in times of uncertainty, and guards against the spread of unfounded rumours and concerns.

Moreover, access to support encompasses the feedback and guidance received from superiors, peers, and subordinates $^{14}$. It can be emotional (caring guidance, empathy, care, love, trust, and concern), appraisal (comparison with others), informational (advice, data), and instrumental (hands-on assistance) $^{15}$. Nurses who are supported by management to act on their expertise and judgment are more likely to believe that high quality outcomes are achievable1.

Empowered environment which apt to have a high degree of access to information, support, resources, and opportunity through putting the customer in the centre and people work cooperatively together to do what is needed. In addition, responsibility, skills, authority, and control are shared and coordination come through continued communication and many decisions ${ }^{16}$.

Empowering nurse managers provide their staff with information beyond what is required to carry out specific patient care on their unit, increasing access to resources needed to meet goals, opportunities for growth by assuming new roles beyond their primary responsibilities, participation on committees both within and outside their work units, and provision of education opportunities to expand knowledge and skills, and build a sense of mutual support and understanding among work group members, with the ultimate goal of improving productivity ${ }^{17,1}$.

Research on the job characteristics model (JCM) by Hackman and Oldham, ${ }^{18}$ found relations between nurses perceptions of specific core characteristics inherent in the job's design which include skill variety, task 
identity, task significance, autonomy, and feedback from the job itself and personal and work outcomes, including empowerment. On the other hand, a number of researchers have found evidence that the five core dimensions of the JCM do not exhaust the set of empowerment-related job attributes ${ }^{1}$. Therefore, Tonges, et al., ${ }^{2}$ added extensions to the core dimensions previously mentioned, which include feedback from agents and required interaction, interpersonal and workrelated job identity, and attribution of results, they developed new tools to measure job characteristics of staff nurses named Staff Nurses Job Characteristics Index (SNJCI).

The skill variety refers to the degree to which a job requires a variety of different activities in carrying out the work, involving the use of a number of different skills and talents of a nurse ${ }^{19}$. While task identity refers to the degree to which a job requires completion of a whole and identifiable piece of work, that is doing a job from beginning to end with a visible outcome. It means the completeness of the tasks done in the job ${ }^{20}$.
Task significance refers to the importance of the job to the served population. In other words, the degree to which the job has a substantial impact on the lives of the people, whether those people are in the immediate organization or in the world at large. Nursing care is important to everyone especially at times of crises or when there is the prospect of serious illness; it is perhaps, hardly surprising that many nurses fell that what they are doing for people is important, meaningful, and significant ${ }^{21}$.

In addition, autonomy means the vertical expansion of responsibility, the amount of decision-making and independence allowed for nurses. It refers to the degree to which the job provides substantial freedom, independence, and discretion to the individuals in scheduling the work and in determining the procedures to be used in carrying it out. The development of nursing as a profession in recent years has meant that nurses are increasingly accountable for the whole cycle of nursing care ${ }^{22}$. 
Feedback related to job is the core of job characteristics which refers to the extent that job itself provides information about employees' performance and it is the degree to which carrying out the work activities required by the job provides the individual with direct and clear information about the effectiveness of his or her performance. Feedback from the job needs to be differentiated from feedback from agents according to Hackman and Oldham ${ }^{18}$ — staff receiving feedback directly from the work itself is more important than feedback from agents. Feedback from the job for nurses would involve seeing the results of their care in the well-being of the patients ${ }^{23}$.

While, feedback from agents refers to extent to which co-workers and supervisors give information about performance, while required interaction refers to the extent to which job requires contact with others. Service jobs are very interpersonal because the client can not be separated from the process. These interpersonal relationships may provide an additional source of perceived job identity. In addition, attribution of results extent to which one can discern effects of own individual actions, attribute outcomes to personal efforts ${ }^{19}$.

In Egypt, different studies related to empowerment and its relations to organization commitment were performed ${ }^{24,25}$. which found significant relationship between them. In another study by El-Sayed ${ }^{26}$ who found significant differences when comparing structural empowerment with job satisfaction. Also, only one study used JCM to compare patient care assignment methods of nurses ${ }^{27}$ which ended to use case method will increase nurses responsibility and work outcomes. However, no attempt study was done to measure staff nurses perception of structure empowerment and job characteristics.

The purpose of the present study was to determine the relationship between staff nurses' perception of structure empowerment and their job characteristics at Mansoura Specialized Medical Hospital. 
MATERIAL and METHODS:

\section{Setting}

The study was conducted at Mansoura Specialized Medical Hospital. It includes all hospital units, they are; cardiology, hepatic and digestive system, diabetic and endocrine, cardiac catheterization, endoscopies, and 3 intensive care units for cardiac, hepatic, and diabetic patients. Hospital capacity is 120 beds.

\section{Sample:}

All staff nurses available $(n=182)$ at the time of study were included with the criteria of having a minimum of one year experience as a staff nurse to be oriented of working conditions.

\section{Research tools:}

Two tools were used for data collection:

The first tool consists of three parts: the first part was demographic characteristics of the sample such as age, years of experience, and educational qualification.

The second part used Conditions for Work Effectiveness Questionnaire (CWEQ) developed by Chandler $^{28}$ to determine perception of staff nurses of structure empowerment. It includes 44 items distributed into 4 themes named: opportunity to learn and grow (19 factors), access to information (10 factors), receiving support (8 factors), and access to resources required to achieve the work (7 factors). An overall empowerment score and a mean percentage score was calculated with a higher score and mean percentage score signifying greater perceived workplace empowerment.

The third part was Organizational Description Opinionnaire (ODO) developed by Laschinger ${ }^{29}$. It includes 2 themes: the first theme used to investigate the perception of staff nurses of structural power characteristics in work environment. It includes (11 factors). The second theme used to measure the perception of staff nurses of their manager's 
power. It includes (11 factors). A nurse with a high mean percentage score reflects higher levels of structure power characteristics of work environment and manager's power ${ }^{19}$.

The second tool was Staff Nurses Job Characteristics Index Questionnaire (SNJCIQ). It used to determine the perception of staff nurses of their job characteristics. The questionnaire depending on (JCM) developed by Hackman and Oldham ${ }^{18}$ and the modification and extension by Tonges, et al. $^{2}$ It includes 100 factors distributed into 7 main themes named: 1) Skill variety (8 factors), 2) Task identity divided into two parts, the first part included factors related to work (16 factors), and the second part contained interpersonal factors (6 factors), 3) Task significance (21 factors), 4) Autonomy (18 factors), 5) Attribution (5 factors), 6) Feedback divided into two parts, the first part was feedback from work itself (6 factors), and the second part was feedback from agents (13 factors), and 7) Required interaction (7 factors). Responses were measured on five point Likert scale ranged from 1 (absolutely disagree) to 5 (strongly agree). In addition, for each factor of the (SNJCIQ) tool, a mean percentage score was computed. A score of $60 \%$ of the mean was considered high, while a score $<60 \%$ of the mean was considered low ${ }^{22}$. In this way, the percentages of nurse scoring above or below average were computed.

\section{Data collection:}

The two questionnaire sheets were translated into Arabic and tested for contents validity by five faculty members in Nursing Administration Department, two members from Mansoura University and three members from Cairo University.

The reliability of the two questionnaires were tested using the test-retest technique. The questionnaires were distributed to 18 staff nurses (excluded from the present study) with a time lapse of one month. Analysis of the data to estimate the test-retest correlation coefficient alpha was $0.84(\mathrm{P}<0.05)$. However, a pilot study was conducted by18 staff nurses 
working at Mansoura Specialized Medical

Hospital (excluded from the present study) and any modifications needed were done based on the responses. The questionnaires were distributed to the study group by the researchers. Time needed to answer both questionnaires sheets were $35-45$ minutes. Data were collected in a five-month period from 1 March to 30 July 2006. Official permission to conduct the study was obtained from the director of Mansoura Specialized Medical Hospital. Staff nurses were asked about participating of the study and they all accepted to collaborate.

\section{Statistical analysis}

The collected data were organized, categorized, analyzed, and tabulated by using SPSS in Windows ${ }^{30}$. Data were presented in the tables by using the maximum score, mean (M), standard deviation (SD), and mean percentage score. Pearson correlation analysis ( $r$ ) was used for assessment of the inter-relationships among various variables. Significant level was threshold at $p<0.05$. 
Table (1): Demographic Characteristics Of Staff Nurses Working At Mansoura Specialized Medical Hospital

\begin{tabular}{|c|c|c|}
\hline \multirow[t]{2}{*}{ Demographic characteristics } & \multicolumn{2}{|c|}{$\mathrm{n}=182$} \\
\hline & No. & $\%$ \\
\hline $\begin{array}{l}\text { 1) Age: } \\
19- \\
24- \\
30- \\
36- \\
42+\end{array}$ & $\begin{array}{c}137 \\
33 \\
8 \\
3 \\
1\end{array}$ & $\begin{array}{l}75.27 \\
18.13 \\
4.40 \\
1.65 \\
0.55\end{array}$ \\
\hline $\begin{array}{l}\text { 2) Experience years: } \\
1- \\
6- \\
12- \\
18- \\
24- \\
30+\end{array}$ & $\begin{array}{c}157 \\
18 \\
3 \\
1 \\
2 \\
1\end{array}$ & $\begin{array}{c}86.26 \\
9.89 \\
1.65 \\
0.55 \\
1.1 \\
0.55\end{array}$ \\
\hline $\begin{array}{l}\text { 3) Educational qualifications: } \\
\text { - B Sc. Degree } \\
\text { - Technical diploma } \\
\text { - Diploma with specialty } \\
\text { - Diploma degree }\end{array}$ & $\begin{array}{c}45 \\
6 \\
3 \\
128\end{array}$ & $\begin{array}{c}24.72 \\
3.3 \\
1.65 \\
70.33\end{array}$ \\
\hline
\end{tabular}

Table (2): Structure Empowerment As Perceived By Staff Nurses At Mansoura Specialized Medical Hospital

\begin{tabular}{|c|c|c|c|}
\hline Structure Empowerment Factors & $\begin{array}{l}\text { Maximum } \\
\text { scores }\end{array}$ & $M \pm S D$ & $\%$ * \\
\hline $\begin{array}{l}\text { A) Condition of work effectiveness: } \\
\text { 1- Opportunity to learn and grow }\end{array}$ & 95 & $69.2 \pm 13.5$ & 72.84 \\
\hline 2- Access to information & 50 & $33.52 \pm 5.75$ & 67.04 \\
\hline 3- Receiving support & 40 & $26.97 \pm 2.29$ & 67.42 \\
\hline 4- Access to resources & 35 & $19.09 \pm 5.43$ & 54.54 \\
\hline $\begin{array}{r}\text { Total } \\
\end{array}$ & 220 & $148.78 \pm 22.14$ & 67.62 \\
\hline $\begin{array}{l}\text { B) Organizational description: } \\
\text { 1- Structure power characteristics } \\
\text { in work environment }\end{array}$ & 55 & $33.13 \pm 9.8$ & 60.23 \\
\hline 2- Manager's power & 55 & $25.36 \pm 5.61$ & 46.11 \\
\hline Total & 110 & $58.49 \pm 5.49$ & 53.17 \\
\hline
\end{tabular}

$\%^{*}=$ mean percentage score 
Table (3): Job Characteristics As Perceived By Staff Nurses At Mansoura Specialized Medical Hospital

\begin{tabular}{|c|c|c|c|}
\hline Job Characteristics Factors & $\begin{array}{l}\text { Maximum } \\
\text { scores }\end{array}$ & $M \pm S D$ & $\% *$ \\
\hline 1- Skill variety & 40 & $30.49 \pm 3.83$ & 76.22 \\
\hline $\begin{array}{l}\text { 2- Task identity } \\
\text { a) Factors related to work } \\
\text { b) Interpersonal factors }\end{array}$ & $\begin{array}{l}80 \\
30\end{array}$ & $\begin{array}{c}62.56 \pm 11.75 \\
19.92 \pm 4.06\end{array}$ & $\begin{array}{l}78.20 \\
66.40\end{array}$ \\
\hline 3- Task significance & 105 & $86.20 \pm 13.53$ & 82.09 \\
\hline 4- Autonomy & 90 & $64.52 \pm 6.53$ & 71.68 \\
\hline 5- Attribution & 25 & $18.44 \pm 1.43$ & 73.76 \\
\hline $\begin{array}{l}\text { 6- Feedback } \\
\text { a) Factors related to work } \\
\text { b) Factors related to persons }\end{array}$ & $\begin{array}{l}30 \\
65\end{array}$ & $\begin{array}{l}23.12 \pm 3.76 \\
38.65 \pm 7.75\end{array}$ & $\begin{array}{l}77.06 \\
59.46\end{array}$ \\
\hline 7-Required interaction & 35 & $22.00 \pm 3.31$ & 62.85 \\
\hline Total & 500 & $365.9 \pm 24.52$ & 73.18 \\
\hline
\end{tabular}

$\%^{*}=$ mean score percentage

Table (4): The Relationship Between Structural Empowerment And job characteristics With Demographic Characteristics.

\begin{tabular}{|l|c|c||c|c||}
\hline \multirow{3}{*}{$\begin{array}{c}\text { Demographic } \\
\text { Characteristics }\end{array}$} & \multicolumn{2}{c||}{ Structure Empowerment } & \multicolumn{2}{c|}{ Job Characteristics } \\
\cline { 2 - 5 } & P-value & r-value & P-value & r-value \\
\hline \hline Age & $0.03^{*}$ & 0.69 & $0.04^{*}$ & 0.66 \\
\hline \hline Years of experience & $0.05^{*}$ & 0.84 & $0.003^{*}$ & 0.99 \\
\hline \hline Educational qualification & $0.04^{*}$ & 0.63 & $0.04^{*}$ & 0.81 \\
\hline
\end{tabular}

${ }^{\star}=P<0.05$ 


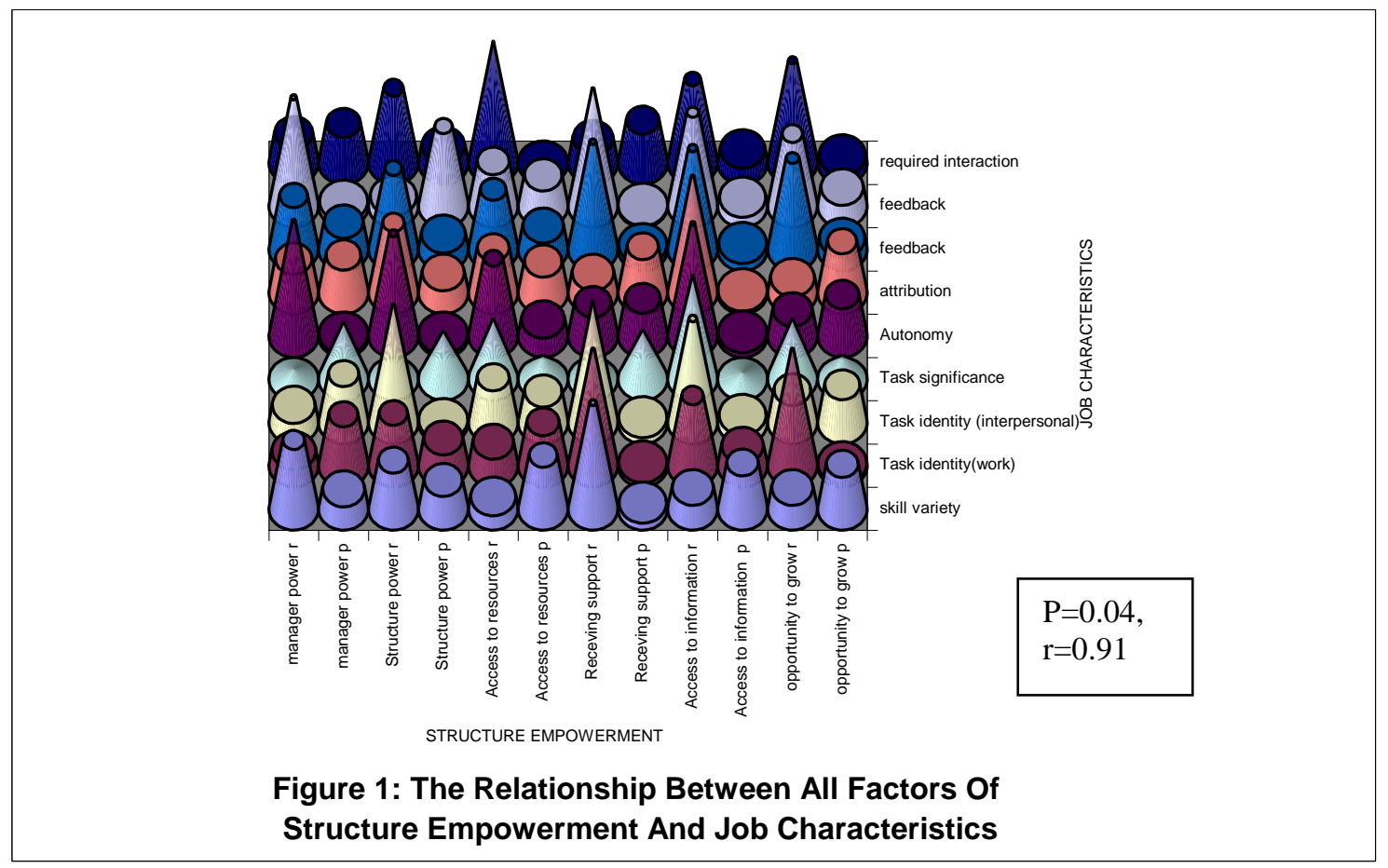

\section{RESULTS:}

Table 1 shows demographic characteristics of staff nurses working at Mansoura Specialized Medical Hospital. Regarding the table, the highest percentage of the staff nurses (75.27\%) was at age group from $(19-<24)$ while the lowest percentage $(0.55 \%)$ was at age group (42+). As regarding to experience years, the highest percentage of staff nurses (86.26\%) was $(1-<6$ experience years) compared with nurses at experience years $(18-<24$, and $30+)$ had the lowest percentage $(0.55 \%)$ equally. In relation to educational qualification, the majority of nurses $(70.33 \%)$ have diploma degree, while the minority of them (1.65\%) have diploma with specialty.

Table 2 shows the maximum scores, $\mathrm{M} \pm \mathrm{SD}$ scores, and mean percentage scores of nurses perception towards the different factors of the structure job empowerment. From the table, 
it can be observed that the highest mean percentage scores $(67.62 \%)$ was related to condition of work effectiveness factors of structure empowerment. Opportunity to learn and grow was the highest mean percentage scores $(72.84 \%)$ of nurses perception, followed by receiving support and access to information (67.42\% and 67.04\%), respectively. As regard organizational description, staff nurses perceived manager's power at the lowest mean percentage scores (46.11\%) of all empowerment factors.

Table 3 shows the $M \pm S D$ scores, and mean percentage scores regarding nurses perception of job characteristics factors. From the table, the total mean percentage scores of job characteristics nurses perception was $73.18 \%$. Regarding to factors, the highest mean percentage scores $(82.09 \%)$ of nurses perception was task significance, followed by task identity factors related to work (78.20\%). While nurses perceived feedback factors related to persons have the lowest mean percentage scores (59.46\%).
Table 4 shows the relationship between structure empowerment and job characteristics with demographic characteristics. From the table, it can be observed that there were significant relationships between structure empowerment and job characteristics with all demographic characteristics. In addition, the table showed that job characteristics had the strongest relationship with years of experience $(p=0.003, r=0.99)$

Figure 1: shows the relationship between all factors of structure empowerment and job characteristics. As seen in this figure, All factors of structure empowerment had significant, strong and positive relationship $(p=0.04, \quad r=0.91) \quad$ with all factors of job characteristics.

\section{DISCUSSION:}

Nurses play an important role in determining both the quality and cost of healthcare services. The level of nurses' empowerment is a critical issue which has 
impact on their performance and effectiveness. In addition, job characteristics are the key factors to exceed penetration nurses' empowerment ${ }^{2}$. So, the present study examined the relationship between staff nurses' perception of structure empowerment and their job characteristics.

The results of the present study revealed that there were a strong and significant relationship between structure empowerment and job characteristics. In overall positions, the explanation of these results could be due to the strong interaction between factors of structure empowerment and job characteristics which were influenced by hospital system as a whole. Hospital system can influence different job characteristics such as structure role assignment, increasing variety of tasks, fostering positive relationships between supervisors and their subordinates, and facilitating collaborative peer relations through nurses empowerment which was observed in promoting opportunities for growth and training, receiving support from supervisors, peers and subordinates, access to resources needed to complete the work, and implications having information about plans and activities that is affect work. Wallach ${ }^{3}$ supported this view.

The relationship between structure empowerment and job characteristics contributes in improving staff abilities and skills during performing their work which reverses their power. In this respect, Suominen et al., ${ }^{31}$ emphasized that nurses who feel strong empowerment have quality in performing skills and challengeable abilities to work, which make possible a strong sense of self-esteem, successful professional performance and progress in their work. In addition, Kraimer, et al., ${ }^{32}$ confirmed that job characteristics represent a set of variables closely related to empowerment but different in at least one important way: job characteristics are designed to measure objective aspects of jobs, whereas empowerment reflects individuals' reactions to their work environments. Thus, job characteristics have been identified as playing 
a key role in determining perceptions of empowerment.

Regarding the empowerment factors, the present study revealed that staff nurses perceived condition of work effectiveness with higher range of power than organizational description. This may be resulted to rigid administration in the hospital in which the most authority gave to physicians with very little opportunity for staff nurses to shared governance or decisions in spite of the greater responsibility expected from them. In addition, the vertical structure of the hospital which places staff nurses far from top management with difficult chance to share in decision making regarding policies, resources, and hospital strategy.

In this point of view, Hechanova, et al., ${ }^{4}$ argued that empowerment assumes that subordinates should be involved in decision making and that they need the authority to accomplish their responsibilities. Moreover, Fagin, et al.., ${ }^{33}$ found that flatted organizational structure placed nurses and head nurses close to top management and the strategic and policy agendas, provided them with control over the resources they needed to be effective, and to make decisions for which they were responsible and accountable.

The present study results revealed that nearly three-fourths of staff nurses in the present study perceived opportunity to learn and grow more empowering them than other factors. In spite of most of staff nurses working at Mansoura Specialized Medical Hospital have diploma degree only in nursing, they are receiving training programs continuously which improve their chance to learn new skills. It interprets the significant relationship explored in these results between opportunity to learn and grow and task identity factors related to work.

Jones et al., ${ }^{34}$ confirmed the difficulties nurses face and disempowered them as a reason of inadequate education "to make a professional" and most nurses have little opportunity to update their knowledge and skills. 
The results of the present study revealed that almost half of staff nurses perceived access to resources as empowering factor. This could be attributed in one hand to finding of some profit units in the hospital increasing its budget and lead to profusion in equipment and facilities in these units to serve this level of patients, while it is little in nonprofits units. Access to resources as this finding revealed can facilitate with interaction supplementation. On the other hand, the staff nurses have not the authority to affect the decision related to number of staff recruited in their units. In the same line, Kuokkanen and Leino-Kilpi ${ }^{35}$ explored many factors that affected nursing empowerment and mentioned resources made readily available from them. Moreover, Patrick and Laschinger ${ }^{1}$ found that access to resources required interaction among staff nurses to carry out their job effectively.

It is supervisory proved that the results of the present study indicated to two-third of staff nurses perception regarding to access to information and receiving support equally influencing their empowerment. While, in real life sites staff nurses have a little chance to inform with changeable organizational goals and policies and their managers only inform them with new policies related to their units, in addition to their need to be supported in difficult situations. These results may be attributed to little authority of unit managers and staff nurses as a result to some traditions in nursing culture with complete obedience, dependency, and implementation of policies without any discussion.

Almost and Laschinger ${ }^{19}$ pointed out that nurses are disempowered as a result to cultures traits such as humility, deference, dependence, obedience, conformity, and traditionalism. In the same line, Kuokkanon and Leino-Kilpi ${ }^{35}$ mentioned that power and knowledge are closely interwoven, where there is power there is also knowledge, and power begets knowledge. Patrick and Laschinger ${ }^{1}$ added that it is important to nurses to have access to knowledge of the organizational goals, technical knowledge, and data to be empowered and feel in control. 
Also, the results of the present study agreed with Almost and Laschinger, ${ }^{19}$ who found that nurses who perceive their managers to be collaborative and supportive are more empowered and more likely to stay with an organization. Moreover, Patrick and Laschinger $^{1}$ supported this view and mentioned that when nurses receive positive feedback and are recognized with rewards for innovative strategies, they feel valued by the organization and pleased that their efforts have been recognized, and when support is lacking, they become frustrated and dissatisfied with their roles. It confirmed the findings of the present study which found significant relationship between the opportunity to receiving support and feedback factors related to both work and persons.

As regard to organizational description, the staff nurses perceived structure power characteristics in work environment at moderate range of power. This may be related to that staff nurses at Mansoura Specialized Medical Hospital had little aspects of trusteeship when they are providing with data needed to accomplish their work and absent sharing in problem solving committees. It is congruent with Suominen et al., ${ }^{31}$ who mentioned that empowered staff nurses have the ability to work in groups by sharing in problem solving committees in order to identify problems and recommend solutions. In the same line, Gallab ${ }^{36}$ found that the work environment that provides nurses with information openly and honestly help them to accomplish their work and increase the availability of structure power characteristics.

Moreover, less than half of staff nurses in the present study perceived that manager's power can empowering them. This may be because of the staff nurses believe that their unit managers have little power and authority, less sharing governance related to work performance and they have little abilities to understand the staff needs. In this respect, Mok and Au-Yeung, ${ }^{37}$ found that leader empowering behaviours such as encourage autonomy and facilitate participative decision making significantly influenced employees' perceptions of formal and informal power and 
access to empowerment structures which lead

to lower level of job tension and increased work effectiveness. They added that nurses perceive themselves to be empowered when their leaders are open to ideas, give them positive criticism, and are fair towards staff.

Regarding job characteristics, the findings of the present study revealed that over two-thirds of staff nurses perceived themselves enriched with skills and characteristics needed to accomplish their job with higher degree of quality and significance. This may be due to the nature of critical role distinguishing the work in Mansoura Specialized Medical Hospital, so, the administration selects the most experienced and proficient nurses from the mother university hospital and redesign their jobs according to work needs. In this respect, Attree $^{38}$ found that jobs that rank high on the core characteristics will be associated with employees responses of high job satisfaction, intrinsic motivation, quality performance, and low absenteeism and turnover. Tappen ${ }^{39}$ supported this view
As regard to factors of job characteristics, task significance was perceived by staff nurses as the dominant mean score percentage of all job characteristics factors. This may be attributed to staff nurses sense of greater responsibility to meet all patients needs as possible, so, they always follow functional methods for providing patients' care and to outdo the shortage of staff and over-workload. In the same line, Tonges, et al., ${ }^{2}$ mentioned that while the pressures of shorter lengths of stay and reducing staffing may create a tendency toward a more fragmented to work, functional approach to care delivery continuity in nurses' patients assignment has been shown to be strongly related to perceived job significance and identity.

In addition, the results in the present study indicated that task identity factors related to work and feedback factors related to work had almost three-fourths mean percentage score of staff nurses perception. An explanation for the later result could be that the continuous desire of staff nurses to 
support and complete their work without any default that may be accountable on it later. They have high response to managers instructions and feedback and accept peer directions toward their performance in spite of their sense of managers powerlessness.

In this respect, Almost and Laschinger, ${ }^{19}$ congruent with this result and mentioned that job feedback is essential to an effective support system through a well developed performance appraisal system by providing the opportunity to recognize and positively reinforce achievements and provide feedback. Moreover, Hechanova, et al., ${ }^{4}$ mentioned that empowerment concerned with positively valued experiences derived directly from a given task feedback.

The present findings indicated that skill variety is the second job characteristics factor staff nurses perceived themselves have it. This may be attributed in one side to increase number of critical diagnostic patients with different needs, which lead to acclimatization on complicated nursing procedures and continuous dealing with difficult clinical situations to meet their needs. On the other side, the effort nurses exert to use their resources effectively. In this respect, Tummers, et al.., ${ }^{40}$ explored that nurses have to perform more tasks in the same amount of time and provide complex patients' care which probably lead to a high workload.

In the same line, Almost and Laschinger, ${ }^{19}$ pointed out that skill variety is concerned most nurses need a combination of clinical, and managerial skills to do their work effectively. In clinical terms, nurses are expected to assess the needs of patients, to plan their care, to provide the care, and to evaluate the patients progress. Managerially, there is an expectation that nurses carry out their work with an increasingly keen eye on resource effectiveness.

The present study findings revealed that staff nurses perceived themselves autonomous with almost two-thirds of mean percentage score. An explanation of these results may be attributed to two sides, the first 
side is that the ignorance of staff nurses to their rights toward sharing decision related to their activities', the second side head nurses attempt to pay attention of staff nurses to improving working condition and co-operation among them to inhibit any complains from over workload. Staff nurses In this respect, Tummers, et al., ${ }^{40}$ mentioned that to increase autonomy, head nurses might pay more attention to the working climate in improving co-operation among nurses and provide courses of team building. Almost and Laschinger $^{19}$ supported this view and explored that nurses felt that structural empowerment resulted in higher levels of collaboration with both physicians and managers, that is, a greater sense of trust and respect, open communication, greater autonomy, and shared responsibility for solving problems and decision-making to effectively accomplish work tasks. Hechanova, et al., ${ }^{4}$ supported this view.

In addition, Attree ${ }^{38}$ found that lack of autonomy has been correlated with job dissatisfaction, stress, burnout, turnover, and low morale which have impact on care quality. This result also was supported with Maryou, ${ }^{41}$ who found that poor communication, shortage of nurses, and over workload decrease or hinder staff nurses autonomy. Moreover, Ulrich, et al., ${ }^{42}$ mentioned that full autonomy is difficult to achieve because nurses must still adhere to policies regarding working hours, general scope, nature of duties, and organizational procedures and can not have their activities' decisions.

Feedback factors related to persons and required interaction had the lowest mean percentage score among staff nurses perception as explored by the result of the present study. This finding can be explained through the nurse managers struggling to increase communication among staff nurses in the time that nurses can not find any time to communicate with each other or with patients themselves as a result of increasing the specialized procedures they performed. In the same respect, Papathanassoglou et al., ${ }^{43}$ found that nurses scored lower in nursing communication tasks, such as providing 
information to patients and especially to family, than in task related to adjustments of medical therapy.

Structure empowerment and job characteristics correlated positively with respondents demographic characteristics as revealed in the result of the present study. An explanation of this result may be attributed to increase level of respect to older, more experience, and proficiency level of nurses. This vision pushes the head nurses as a traditional act to bury the older nurses from night shift. In the other exploration, with exceeding in the job and increasing staff nurses years of experience, they could be logically identify their job from the two domains, quantity and quality, increase their task significance and variety, as well as the level of communication and interaction with supervisors, physicians, and peers.

In this point of view, Ellefsen and Hamilton, ${ }^{44}$ incongruent with their result, they mentioned that age and experience have an influence on the formal and informal aspects of the job, and older people and those with a long time in the work place might not always regarded as an asset.

\section{CONCLUSION AND RECOMMENDATIONS:}

The findings of the present study revealed a strong relationship between staff nurses' perception of structure empowerment and their job characteristics at Mansoura Specialized Medical Hospital. These results explored that structure empowerment and job characteristics are two faces to one coin. Job characteristics are affected by both receiving support from manager, peers, and physicians, and access to resources. As well as, empowerment is affected by task identity factors related to work, feedback factors related to work, and their required interaction. This research takes the initial step toward understanding the job characteristics and empowerment in a hospital setting in an Egyptian culture.

In the light of the results of the present study, the following recommendations are a few of many that will be a giant step forward in 
the development of nursing and nurses' job design as an administrative significant profession in the health care system of Egypt.

1- Apply job characteristics model nutrients to empower staff nurses, improve the quality of patient care, and redesign job standard assort with nurses abilities and work requirements.

2- Employ the relationship resulted in the present study as a framework to develop a new measuring tool for monitoring and evaluation of nursing service provision and empowering practice.

3- Enhance staff nurses' empowerment to accomplish the hospital goals through increase level of autonomy with some freedom related to their activities' decisions which were enforced by sharing in problem solving and decision making committees.

4- Distribution of resources according to the patient needs in profits and nonprofits units to facilitate work achievement and increase job significance.

5- Provision of up-to-date information regarding work through training programs, positive feedback, and well communication and interaction with patients and their families, peers, managers, and physicians can play an important role in staff nurses empowerment.

\section{REFERENCES}

1. Patrick $\mathbf{A}$, Laschinger $\mathbf{H}$. The Effect Of Structural Empowerment And Perceived Organizational Support On Middle Level Nurse Managers' Role Satisfaction. Journal of Nursing Management. 2006; 14,13-22.

2. Tonges $\mathbf{M}$, Rothstein $\mathbf{H}$, Carter $\mathbf{H}$. Source Of Satisfaction In Hospital Nursing Practice., A Guide To Effective Job Design., Journal Of Nursing Administration. 1998; 28(5): 47-61.

3. Wallach V. Job Characteristics and Organizational Predictors of Structural Empowerment Among Paraprofessionals Within Human Service Organizations: An Exploratory Study. Administration In Social Work Journal. 2006; 30(1): 95-115.

4. Hechanova M, Alampay R, Franco E. Psychological Empowerment, Job Satisfaction And Performance Among Filipino Service Workers. Asian Journal of Social Psychology. 2006; 9: 72-5. 
5. Varjus S., Suominen T., \& Leino-Kilpi H., Autonomy Among Intensive Care Nurses In Finland., Intensive And Critical Care Nursing. 2003; 19:31-40.

6. The Oxford English Dictionary. Oxford University Press, Oxford., in: Henderson S., (2003); Power Imbalance Between Nurses And Patients. A Potential Inhibitor Of Partnership In Care. Journal Of Clinical Nursing. 1996; 12:501-8.

7. Kanter R. Organizational Truss And Empowerment In Restructured Healthcare Settings. In: Laschinger $\mathrm{H}$., Finnegan J., Shamiam J., \& Casier S. Journal of Nursing Administration. 1977; 30(4) 26-35.

8. Kanter R. Men And Women Of The Corporation. New York: Basic Books; 1993. 65-75.

9. Valentine N. Challenges And Opportunities In Psychiatric-Mental Health Nursing. Journal Of Nursing Administration. 2000; 48(5):238-9.

10. Trofino J. In: Hein E. : Contemporary Leadership Behavior. Lippincott; New York: $5^{\text {th }}$ Ed. 1992. 177-186.

11. Karen J. Clinical And Nursing Staff Development; Current Contemporary And Competencies. $2^{\text {nd }}$ Ed., Future Focus, Lippincott; Philadelphia: 1998. 341-3.

12. Hall L, Pink G, Johnson L, Schraa E. Development Of A Nursing Management Practice. Atlas, Part2. Variation In Use Of Nursing And Financial Resources. Journal Of Nursing Administration. 2000; 30(9):440-8.

13. Laschinger $\mathbf{H}$, Havens $\mathbf{M}$. Staff Nurse Work Empowerment And Perceived Control Over Nursing Practice. Conditions Of Work Effectiveness.
Journal Of Nursing Administration. 1996; 26(9):27-35.

14. Teasdale K, Brcklehurst N, Thom N. Clinical Supervision And Support For Nurses: An Evaluation Study., Journal of Advanced Nursing. 2001;33(2):216-24.

15. Sabiston A, Laschinger H. Staff Nurse Work Empowerment and Perceived Autonomy. Testing Kanter's Theory Of Structural Power In Organizations. Journal of Nursing Administration.1995; 25(9):42-50.

16. Scott C, Jaffe D. Empowerment; A Practical Guide For Success. Menlo Park CA: Crisp; 1991. 308-15.

17. Klakovich M. Registered Nurse Empowerment; Model Testing And Implications For Nurse Administrators. Journal of Nursing Administration. 1996; 26(5) 29-35.

18. Hackman J, Oldham G. Work design. Reading, Massachusetts: AddisonWesley;1980.114-21.

19. Almost J, Laschinger H. Workplace Empowerment, Collaborative Work Relationships, And Job Strain In Nurse Practitioners. Journal of The American Academy of Nurse Practitioners. 2002; 14(9):408-20.

20. Thomas $\mathbf{P}$, Palfrey C. Evaluation; Stakeholder-Focused Criteria. Social Policy And Administration.1996; 30:12542.

21. Pilon B. Outcomes And Surprises Of Work Redesigning: How Other Leaders Are Coping With Changes. Journal of Nursing Management. 1998; 29(8):445 .

22. Huber D. Leadership And Nursing Care Management. Philadelphia: WB Saunders; 2000. 151-152. 
23. Eaton N, Thomas P. Job Diagnostic Surveys Of Paediatric Nursing: An Evaluative Tool. Journal Of Nursing Management. 1997; 5,167-73.

24. Abd El-Aal N. Nurses Perception of Job Empowerment And Organizational Commitment In Critical Care Units Of Alexandria Main University Hospital., Unpublished Master Thesis. Faculty Of Nursing. Alexandria University; 1999.

25. El-Shaer A. Staff Nurses Perception Of Job Empowerment And Organizational Commitment At Mansoura University Hospital. Unpublished Master Thesis. Faculty Of Nursing. Cairo University. 2002.

26. El-Sayed N. Relationship Between Staff Nurses Perception Of Job Empowerment And Their Job Satisfaction. Bulletin Of High Institute Of Public Health. 2002; 32(3):521-40.

27. Mohamed A. Using The Job Characteristics Model To Compare Patient Care Assignment Methods Of Nurses. Eastern Mediterranean Health Journal. 2004; 10(3):389-405.

28. Chandler G. The Relationship of Nursing Work Environment To Empowerment And Powerlessness., In: Laschinger M, Shamian J.: Staff Nurses And Nurse Manager's Perceptions Of Job Related Empowerment Self Efficacy. Journal Of Nursing Administration. 2000;24(10):38-41.

29. Laschinger $\mathbf{H}$. Organizational Description Opinionative. Unpublished Data Collection Instrument.; London University Of Western Ontario: 1991.

30. Windows. (SPSS) Statistical Package for the Social Sciences. Release 10: Chicago, USA: SPSS ANC; 1999.

31. Suominen T, Savikko N, Kukkurainen M, Kuokkanen I, Doran D. Work
Related Empowerment Of The Multidisciplinary Team At The Rheumatism Foundation Hospital. International Journal Of Nursing Practice. 2005; 12: 94 - 104.

32. Kraimer $\mathbf{M}$, Seibert $\mathbf{S}$, Liden $\mathbf{R}$ Empowerment As A Multidimensional Construct; A Test Of Construct Validity. Educational And Psychological Measurement. 1999; 59(1) 127-42.

33. Fagin C, Maraldo P, Mason D. Are You Sure Nurses Are Autonomous? Are Not Physicians Calling The Shots?. Review Article Submitted To The Center For Nursing Advocacy. Inc., www.nursingadvocacy.org. 2006.

34. Jones $\mathbf{P}$, O'Toole $\mathbf{M}$, Hoa $\mathbf{N}$, Chau $\mathbf{T}$, Muc P. Empowerment Of Nursing As A Socially Significant Profession In Vietnam. Journal Of Nursing Scholarship. 2000; 3 ${ }^{\text {rd }}$ Quarter, 317-21.

35. Kuokkanen L, Leino-Kilpi H. Power And Empowerment In Nursing; Three Theoretical Approaches. Journal of Advanced Nursing. 2000; 31(1):235-41.

36. Gallab S. Power and The Role of The Nurse Manager. Review Article Submitted To The Scientific Committee for Promotion of Teaching Staff. 2001. Egypt.

37. Mok E, Au-Yeung B. Relationship Between Organizational Climate And Empowerment Of Nursing In Hong Kong. Journal Of Nursing Management. 2002; 10,129-37.

38. Attree M. Nursing Agency And Governance: Registered Nurses Perceptions. Journal Of Nursing Management. 2005; 13,387-96.

39. Tappen R. Nursing Leadership And Management: Concept And Practice. $3^{\text {rd }}$ ed. Philadelphia: FA Davis; 1995. 445453. 
40. ummers G, Landeweerd $\mathbf{J}$, van Merode G. Organization, Work and Work Reaction: A Study of The Relationship Between Organizational Aspects of Nursing and Nursing Work Characteristics and Work Reactions. Scandinavia Journal Of Caring Sciences. 2002; 16:52-8.

41. Maryou M. Nurses' Autonomy Influence of Nurse Managers' Actions. Journal of Advanced Nursing. 2004; 45 (3): 326-36.

42. Ulrich C, Soeken K, Miller $\mathbf{N}$. Predictors of Nurse Practitioners' Autonomy; Effects of Organizational,
Ethical, and Market Characteristics. Journal of The American Academy of Nurse Practitioners. 2003;15 (7): 367-75.

43. Papathanassoglou E, Tseroni $M$, Vazaiou G, Kassikou J, Lavdaniti M. Practice And Clinical Decision-Making Autonomy Among Hellenic Critical Care Nurses. Journal of Nursing Management. 2005; 13:154-64.

44. Ellefsen B, Hamilton G. Empowered Nurses? Nurses In Norway And The USA Compared. International Council Of Nurses. International Nursing Review. 2000; 47,106-20. 